\title{
Evaluation of the efficacy of intramuscular versus intramammary treatment of subclinical Streptococcus agalactiae mastitis in dairy cows in Colombia
}

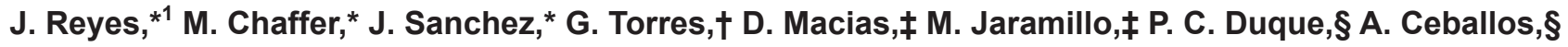 \\ and G. P. Keefe* \\ *Department of Health Management, Atlantic Veterinary College, University of Prince Edward Island, Charlottetown, Prince Edward Island, \\ C1A 4P3 Canada \\ †Tropical Medicine Colombian Institute, CES University, CRA. 43A No. 52 sur-99 Medellín, Antioquia, Colombia \\ ¥Cooperativa COLANTA, CRA 64C, 72-160 Medellín, Colombia \\ §Department of Agricultural and Livestock Sciences, Universidad de Caldas, Calle 65 \#26-10, Manizales, Caldas, Colombia
}

\section{ABSTRACT}

A randomized controlled trial was performed in 17 Colombian dairy herds to determine the cure risk among cows subclinically infected with Streptococcus agalactiae exposed to 2 antibiotic therapies. Composite milk samples were collected before milking at the onset of the trial (pretreatment) and 2 subsequent times over a period of approximately $63 \mathrm{~d}$. The intramammary application (IMM) of ampicillin-cloxacillin was compared with the intramuscular application (IM) of penethamate hydriodide, and cure risks after an initial and retreatment application were assessed. Cure risk after the initial treatment was higher $(82.4 \%)$ for the IMM treatment than for IM therapy $(65.8 \%)$. However, no difference was observed in the cure risk of refractory cases after retreatment $(\mathrm{IMM}=52.6 \%$ vs. $\mathrm{IM}=51.2 \%)$. The cumulative cure risk (both initial and retreatment) was 90.4 and $82.9 \%$ for the IMM and IM products, respectively. A 2-level random effects logistic model that controlled for pretreatment cow-level somatic cell count, indicated that IM treatment $($ odds ratio $=0.37)$ had a lower cure risk than IMM and a tendency for a lower cure risk with increasing baseline somatic cell count. Our findings suggest that both products and administration routes can reduce the prevalence of $S$. agalactiae in affected herds, but the IMM product had a better efficacy in curing the infection. In addition to the treatment protocol, the cow somatic cell count should be considered when making management decisions for cows infected with $S$. agalactiae.

Key words: somatic cell count, Streptococcus agalactiae, subclinical mastitis, antibiotic

Received December 6, 2014.

Accepted April 22, 2015.

${ }^{1}$ Corresponding author: jreyes@upei.ca

\section{INTRODUCTION}

Bovine mastitis continues to be the most economically important disease in dairy cattle (Gröhn et al., 2004) and is caused by a broad spectrum of infectious agents. Streptococcus agalactiae is considered to be a major contagious pathogen for bovine mastitis, and the primary reservoir of the pathogen and source of infection for healthy animals is the udder of infected herdmates (Keefe, 1997).

The prevalence of $S$. agalactiae has been reduced in North American and European countries with longstanding extension programs (Keefe, 2012). However, in the Scandinavian countries, particularly Denmark a reemergence of $S$. agalactiae has been documented (Zadoks et al., 2011; Katholm et al., 2012). Without systematic surveillance it is uncertain if this is also the case in other European countries or North America. By contrast in South America, S. agalactiae has consistently remained an important pathogen, with a herd-level prevalence of $60 \%$ in Brazil and $42 \%$ in Colombia, and a cow-level prevalence of $11 \%$ in Uruguay (Gianneechini et al., 2002; Duarte et al., 2004; Keefe et al., 2011). In a Colombian study, among quarters with elevated California mastitis test, $34.7 \%$ had S. agalactiae (Ramírez et al., 2014).

A recent study in Colombia showed that the presence of $S$. agalactiae in a herd has a significant effect on milk quality. That study reported that positive herds had a $70 \%$ higher bulk tank milk somatic cell count (BTSCC) than negative herds. Moreover, the total bacteria burden in the positive tanks was almost twice as high as in the negative tanks (Keefe et al., 2011).

The control of this pathogen remains important from a global health perspective. The presence of this pathogen in the cows and bulk tank suggests significant control problems in the herd (Edmondson, 2011) and the need to improve within-herd biosecurity (Keefe, 2012). Eradication of the agent is considered the ultimate goal and this strategy has been in use since the 
mid-20th century. For example, in 1933 the first successful eradication program was reported and consisted of a combination of laboratory testing, segregation, and elimination of infected animals (Wilkinson, 1965). Since the beginning of control and eradication programs, the use of penicillin-based products has been recommended (Wilkinson, 1965). Streptococcus agalactiae remains highly susceptible to antimicrobials (Makovec and Ruegg, 2003), in particular to $\beta$-lactam-based products (Erskine et al., 2002; Edmondson, 2011). Continued sensitivity to antimicrobials has been an important factor in the success of control programs that combine lactational treatment with other recommendations, such as postmilking teat disinfection and dry cow therapy (Keefe, 2012).

The prevalence of mastitis caused by $S$. agalactiae can be successfully reduced with an antimicrobial agent-treatment program and adequate herd management to limit the incidence of new infections. A popular approach for control and eradication is blitz therapy, which is the treatment of all lactating cows simultaneously regardless of infection status; however, this method is commonly modified so that only the culturepositive animals are treated (Edmondson, 2011). The main routes of administration for the treatment of mastitis are intramuscular (IM) and intramammary (IMM; Sérieys et al., 2005). The selection of treatment route should be made using the following criteria: integrity of the biological barriers of the udder; location of the bacteria in consideration of the physiochemical characteristics of the antimicrobial agent; stage at which the treatment is initiated; and severity of the pathology (Du Preez, 2000). The IMM route is commonly chosen (Du Preez, 2000; Sérieys et al., 2005) and, in this case, the selected antimicrobial agent should exhibit high lipid solubility to allow the product to move through lipid-rich membranes; product efficacy is correlated with the duration of effect in the milk (Gruet et al., 2001). Streptococcus agalactiae is sensitive to IMM treatment, as infections in both lactating and dry cows respond to IMM therapy with $\beta$-lactam-based products with a cure risk of approximately $90 \%$ (Tyler et al., 1992). As a result, treatment by this route will result in the elimination of a high number of infections in a cost-effective manner (Keefe, 1997). The IM route should only be considered for compounds that are highly lipophilic and able to cross the epithelia into the mammary gland parenchyma (Gruet et al., 2001). Additionally, IM products should continue to be active in inflammatory secretions and should achieve effective therapeutic concentrations within the mammary gland (Pyörälä, 2006). The IM route has been reported as effective for the treatment of $S$. agalactiae (Tyler et al., 1992). Across pathogen species, IM treatment has been suggested when more than 1 quarter is affected, in cases of chronic subclinical infections (Barkema et al., 2006), or when the infection is clinical in nature (Pyörälä, 2006).

Several studies have examined cure risk for subclinical S. agalactiae and other streptococci infections after either IM or IMM therapy versus either negative controls or other products with the same route of administration. One study compared cure risk for clinical mastitis between IM and IMM treatment and found no difference (Sérieys et al., 2005). However, their study had very few (7 of 312) S. agalactiae-associated cases. No studies have focused on a direct comparison of IM and IMM therapy for subclinical $S$. agalactiae infections.

In Colombia, the high prevalence of $S$. agalactiae, combined with climatic factors, hand milking, and variable adoption of hygienic practices makes the control and eradication of $S$. agalactiae particularly challenging. Growing interest from the dairy industry and academia has led to efforts to determine a more efficient treatment strategy for the country-specific herd conditions. This treatment strategy also needs to address the best treatment regimen (administration route, product) that addresses the concerns of the producers.

The present study evaluated the efficacy of 2 products - ampicillin and cloxacillin IMM infusion (Masticillin Lactation, Bayer, Leverkusen, Germany), which was reported to have a robust IMM distribution (Gruet et al., 2001), and IM penethamate injection (Mamyzin P, Boehringer Ingelheim GmbH, Ingelheim, Germany), a weak base lipophilic compound with reported high concentrations of benzylpenicillin in the mammary gland (McDougall, 1998) - for the treatment of S. agalactiae in dairy cows from the departments of Antioquia and Caldas, Colombia. The methodology was a randomized clinical trial, controlling for the herd effect and individual SCC with the outcome of cow bacteriological cure.

\section{MATERIALS AND METHODS}

\section{Sample Size}

The minimum number of cows to be included in the controlled clinical trial was estimated based on methodology for the comparison of 2 proportions using the methods reported by Dohoo et al. (2009), although a more robust hierarchical methodology was eventually used. For the sample size calculation, the following assumptions were made: a 2 -sided $\chi^{2}$ test with $\alpha$ of 0.05 and a power $(1-\beta)$ of 0.80 . We assumed an expected bacteriological cure proportion for the IMM product of 
$95 \%$ and for the IM product of $85 \%$, and used an allocation ratio of 1:1. A 2-sided test was selected to reflect the uncertainty of the direction of the treatment effect, given previous experiences reported in the region. A sample size of 282 cows was calculated; therefore, 141 animals were required in each treatment group. The sample size calculation did not account for farm effects; however, these effects were included in the final models and, as anticipated, indicated minimal variability among farms after meeting the selection criteria described herein.

\section{Herd and Cow Selection, Allocation to Treatment, and Sampling Schedule}

The study was conducted in 17 herds from the departments of Antioquia and Caldas, Colombia. The study targeted herds with a BTSCC greater than 350,000 cells $/ \mathrm{mL}$ (typically $>600,000$ cells $/ \mathrm{mL}$ ) that were positive for $S$. agalactiae in the bulk tank milk in the last month. A convenience sample of herds meeting these criteria was defined and all the lactating cows were sampled between July 8, 2013, and May 20, 2014, and cows were allocated to treatments between July 15, 2013, and June 9, 2014. Within these herds, a total of 1,104 lactating cows were screened for $S$. agalactiae infection with composite milk sampling. Study cows were sampled at 3 different times over an average period of $63 \mathrm{~d}$. The first sampling included all the cows in lactation, and these results provided a baseline measure of the pretrial prevalence of the pathogen as well as identified cows for the controlled clinical trial. Cows were included in the clinical trial if they were culture positive for $S$. agalactiae on the first milk sample, had not received treatment with antibiotics for any disease in the previous month, and were not expected to be dried off before collection of follow-up samples.

Infected cows were randomly allocated into treatment groups within each farm. A unique cow code was assigned for each infected animal in an Excel (Microsoft Corp., Redmond, WA) spread sheet and random allocation for infected animals within each herd was performed using EPIDAT software, version 4.0 (Comesaña et al., 2012). All cows that met the inclusion criteria were included, and assignment to treatment was balanced within each herd. A treatment allocation list was developed for each herd and was sent by email to the field administrators of the project.

The initial treatment was administered $11 \mathrm{~d}$ after the first milk sampling and a second sampling took place $4 \mathrm{wk}$ posttreatment. Cows that remained infected with $S$. agalactiae received a repeat treatment with the same product used in the initial round occurring $11 \mathrm{~d}$ after the second milk collection. A final milk sampling was conducted on all refractory cases 4 wk after the repeated treatment. Individual cow laboratory data, including SCC and milk composition, were generated for each sample. Other individual variables, such as DIM and parity, were not included due to lack of individual cow records for the herds.

\section{Treatments}

The 2 treatments were as follows: (1) an IMM infusion of a combination of $200 \mathrm{mg}$ of cloxacillin and 75 $\mathrm{mg}$ of ampicillin (Masticillin Lactation, Bayer), which was administered in all 4 quarters postmilking for 3 consecutive milkings; and (2) an IM injection of $5 \mathrm{~g}$ of penethamate hydriodide (Mamyzin $\mathrm{P}$, Boehringer Ingelheim $\mathrm{GmbH}$ ), which was administered daily for 3 consecutive days. Treatment was at the cow level and the IMM product was applied to all 4 quarters to provide similar coverage as the IM therapy. All culturepositive cows meeting the selection criteria described above were treated as per this protocol.

\section{Milk Sampling Technique}

Two composite milk samples were taken at each sampling time. For SCC evaluation, subsequent to udder preparation, milk was stripped from each quarter and an approximately equal volume of milk was collected from each teat into a $30-\mathrm{mL}$ sample vial containing bronopol for preservative. Next the udder was prepared for sterile sampling using the National Mastitis Council protocol (Hogan et al., 1999). A second composite sample was collected aseptically from the 4 quarters of the udder, with equal volumes per quarter placed into a sterile $30-\mathrm{mL}$ sample vial without preservative. Samples were transported on ice to the laboratories described herein.

\section{Laboratory Procedures}

Samples were processed for microbiological analysis at the Colombian Tropical Medicine Institute laboratory (ICMT-CES; Medellin, Colombia) and at the Milk Quality Laboratory of the University of Caldas (Manizales, Colombia) using a standard protocol. For the microbiological diagnosis, the milk samples were gently inverted before being inoculated onto the culture medium. A volume of $0.01 \mathrm{~mL}$ was inoculated on esculin blood agar and the plate was incubated at $37^{\circ} \mathrm{C}$. After $24 \mathrm{~h}$, the plates were examined for growth and if the organism was not detected the plates were reincubated for another $24 \mathrm{~h}$ ( $48 \mathrm{~h}$ total). Colonies were considered 
to be suspect $S$. agalactiae using the following criteria: esculin-negative colonies with a diameter between 1 and $3 \mathrm{~mm}$, without regard to hemolysis pattern. For all suspect colonies, a catalase test and Gram staining were performed. Catalase-negative and gram-positive colonies were processed with the confirmatory Christie, Atkins, Munch-Petersen (CAMP) test in blood agar, which included a further incubation for $24 \mathrm{~h}$ at $37^{\circ} \mathrm{C}$ with a streak of Staphylococcus aureus to observe the characteristic reaction (Hogan et al., 1999). The SCC analysis was performed using a CombiFoss 6000 (Foss Electric, Hillerød, Denmark) at the Central Payment and Quality Control Laboratory of the Cooperative Colanta (San Pedro, Colombia).

\section{Bacteriological Cure Definition}

Cure was defined at the cow level. A cow was considered cured if she was previously culture-positive for S. agalactiae and was subsequently culture-negative at the 4-wk follow-up culture. Cure was assessed for initial treatment (samples 1 and 2) and retreatment of refractory cases samples (2 and 3), independently. A single posttreatment sample was used to determine both treatment and retreatment cure risks. The initial treatment regimen was the first exposure of the cows to 1 of the products and routes; when a cow failed to cure, a second treatment was performed using the same product and route as the initial treatment. No more than 2 treatment attempts per cow were used in our study.

\section{Statistical Analysis}

Descriptive statistics for participant herd demographics, production, milking management, and S. agalactiae within-herd prevalence were generated. Cow-level cure risk data after the initial and retreatment were generated for descriptive purposes. The proportion of cured cows (previous positive animals that were subsequently negative) was determined separately after sampling 2 (initial treatment cure) and 3 (re-treatment cure). Additionally, a cumulative cure risk was calculated using as the numerator the total cured animals for both initial treatment and retreatment and as the denominator the initial number of treated animals in both IM and IMM groups at the start of the interventions.

Subsequently, a 2-level logistic regression model with $S$. agalactiae cure after the first treatment as the outcome variable and herd as the random effect was developed to assess the effect of treatment. The first logistic model used was as follows:

$$
\begin{gathered}
\operatorname{Logit}_{\left(\mathrm{p} S . \text { agalactiae cure }_{(i j)}\right.}= \\
\beta_{0}+\beta_{1} \text { Treatment }_{(i)}+\mu_{(j)}, \\
\mu_{(j)} \sim N\left(0, \sigma^{2}\right),
\end{gathered}
$$

where p $S$. agalactiae cure was the cure risk after 1 treatment; Treatment ${ }_{(i)}$ was the effect of treatment in cow $(i=$ corresponded to cow $)$ defined as a binary variable $(0=\mathrm{IMM}, 1=\mathrm{IM}) ; \mu_{(j)}$ was the random effect of herd $(j=$ corresponded to herd; $\mathrm{n}=17)$; and $\sigma^{2}$ was the herd variance. Herd was modeled as a random effect to explore the herd-associated variation of the outcome. The inclusion of herd as a fixed effect would have generated several nonsignificant coefficients in the model. The variation explained by herd was calculated using the latent variable approach for this type of model (Dohoo et al., 2009).

A second model was developed to assess the effect of the initial individual SCC on the cure risks and to perform marginal predictions for the cure risk in an average herd over a range of baseline SCC values. Normality was assessed for all quantitative variables used in the models and individual cow SCC was natural log-transformed $\left(\mathbf{L N S C C} \mathbf{C}_{\mathbf{1}}\right)$ for analysis. For the purpose of interpretation, the natural log of SCC was back-transformed. Once the final models were reached, the fit was evaluated by examination of residual plots (Dohoo et al., 2009). The data analysis was carried out with STATA 12 (StataCorp, 2011).

\section{RESULTS}

The 17 herds enrolled in the study had a mean of 64 cows in lactation, with a minimum of 17 and a maximum of 133 lactating cows. The mean bulk tank volume per day at the beginning of the treatments was 1,136 L (17.8 L/cow per day). The mean BTSCC over the first sampling period was 672,810 cells $/ \mathrm{mL}$ with a range of 354,000 to 972,000 cells/mL. Finally, $28.5 \%$ of these farms used machine milking, $67.5 \%$ were manual, and $4.0 \%$ used both. Mean within-herd prevalence of S. agalactiae among the 17 herds was $27.4 \%$, with a minimum of $5.6 \%$ and a maximum of $60.0 \%$.

The average time between initial culture and treatment was $11 \mathrm{~d}(\mathrm{SD}=4.5)$. The second sampling took place on average $26 \mathrm{~d}$ after the first treatment $(\mathrm{SD}=$ 5.8 ), with treatment of refractory cases occurring an average of $10 \mathrm{~d}$ after this second culture $(\mathrm{SD}=4.2)$. Final milk cultures took place an average of $22 \mathrm{~d}$ after retreatment $(\mathrm{SD}=6.5)$.

Of the 1,104 cows screened, a total of 308 were found to be $S$. agalactiae-positive. Forty-two animals were 
Table 1. Animal cure risk for initial and retreatment regimens, comparing intramammary treatment (Masticillin Lactation, Bayer, Leverkusen, Germany) and intramuscular treatment (Mamyzin P, Boehringer Ingelheim GmbH, Ingelheim, Germany) of Streptococcus agalactiae in 248 animals within 17 herds in Antioquia and Caldas, Colombia

\begin{tabular}{lccc}
\hline & & \multicolumn{2}{c}{ Cured animals } \\
\cline { 3 - 4 } Item & $\begin{array}{c}\text { Total treated, } \\
\text { no. }\end{array}$ & no. & $\%$ \\
\hline First treatment & & & \\
Intramammary & 125 & 103 & 82.40 \\
Intramuscular & 123 & 81 & 65.85 \\
Total & 248 & 184 & 74.19 \\
Second treatment & & & \\
Intramammary & 19 & 10 & 52.63 \\
Intramuscular & 41 & 21 & 51.22 \\
Total & 60 & 31 & 51.67 \\
\hline
\end{tabular}

removed from the study because they had recent antibiotic treatments for clinical mastitis or other diseases, or were to be dried off before follow-up samples could be taken. As a result, a total of 266 were initially entered into the study. To determine the initial cure risk, both first and second samplings were required. Eighteen animals did not have a follow-up sample, leaving 248 sets of paired data available to calculate initial cure risk. To calculate the retreatment cure risk, a third sample was required for cases refractory to the initial treatment. Sixty of the 64 refractory cases had results from this third sampling available for analysis.

Table 1 shows the proportion of cure for each treatment after the first and second application. The IMM treatment with the combination cloxacillin and ampicillin product $(\mathrm{n}=125)$ resulted in a cure risk of 82.4 versus $65.8 \%$ for the IM penethamate treatment $(\mathrm{n}=$ 123). Sixty animals were retreated based on the followup milk culture results (41 in the IM group and 19 in the IMM group), resulting in a 52.63 and $51.22 \%$ cure risk for the IMM and IM treatments, respectively. The cumulative cure risk for the IMM product was $90.4 \%$
$(113 / 125)$ and for the IM product was $82.9 \%(102 / 123)$. Two-level logistic models were created to examine the effect of treatment on S. agalactiae cure risk. The first model (data not shown) considered only the effect of treatment group on cure risk and included the full data set of 248 animals within the 17 farms, controlling for herd as a random effect. According to the model presented in Table 2, which included both the effect of treatment and $\mathrm{LNSCC}_{1}$, the group of cows receiving IM treatment were on average 2.7 times $(1 / 0.37)$ more likely to remain infected after the first treatment as compared with the group of animals receiving IMM product. The model herd variance was 0.197 ( $\mathrm{SE}=$ 0.215 ) and, using the latent response variable approach, the intraclass correlation coefficient (ICC) was $5 \%\left[\mathrm{ICC}=0.197 /\left(0.197+\pi^{2} / 3\right)\right]$ (Dohoo et al., 2009). In this model, the number of observations was reduced by $47(\mathrm{n}=201)$ because of missing pretreatment SCC values. The effect of $\mathrm{LNSCC}_{1}$ had a trend, although not significant $(P=0.074)$, with a negative coefficient indicating that elevated SCC at the time of treatment was associated with a trend for a lower cure risk. No interaction was noted between treatment (IMM vs. IM) and the effect of SCC on the cure risk outcome. Figure 1 illustrates the marginal log odds of cure in an average herd at various pretreatment SCC levels. A clear separation of the lines was observed, indicating a superior cure risk for IMM therapy and a trend toward lowered cure risk at higher SCC for both treatments. The lines were relatively parallel, indicating that the apparent SCC effect was not dependent on treatment type.

\section{DISCUSSION}

The objective of our controlled clinical trial was to evaluate 2 treatments for $S$. agalactiae when administered to subclinically infected cows; the outcome of interest was cure risk after treatment. Composite milk

Table 2. Two-level logistic regression model comparing intramammary treatment (Masticillin Lactation, Bayer, Leverkusen, Germany) and intramuscular treatment (Mamyzin P, Boehringer Ingelheim GmbH, Ingelheim, Germany) of Streptococcus agalactiae in 201 animals within 16 herds in Antioquia and Caldas, Colombia

\begin{tabular}{|c|c|c|c|c|c|c|c|c|}
\hline S. agalactiae cure risk ${ }^{1}$ & $\begin{array}{l}\text { Odds } \\
\text { ratio }\end{array}$ & Parameter & $\mathrm{SE}$ & Estimate & $z^{2}$ & $P>\mathrm{z}$ & \multicolumn{2}{|c|}{$95 \% \mathrm{CI}^{3}$} \\
\hline \multicolumn{9}{|c|}{ Reference category: Intramammary } \\
\hline Intramuscular & 0.37 & & 0.13 & & -2.93 & 0.003 & 0.19 & 0.72 \\
\hline $\mathrm{LNSCC}_{1}$ & 0.80 & & 0.10 & & -1.79 & 0.074 & 0.62 & 1.02 \\
\hline Intercept & 22.07 & & 20.15 & & 3.39 & 0.001 & 3.69 & 132.11 \\
\hline Herd random effects & & Variance & 0.23 & 0.17 & & & 0.01 & 2.36 \\
\hline
\end{tabular}

${ }^{1} \mathrm{LNSCC}_{1}=$ natural logarithm of the individual SCC at the beginning of the intervention.

${ }^{2} \mathrm{z}$-value used in testing the null hypothesis of the coefficient.

${ }^{3} \mathrm{LL}=$ lower limit; $\mathrm{UL}=$ upper limit. 


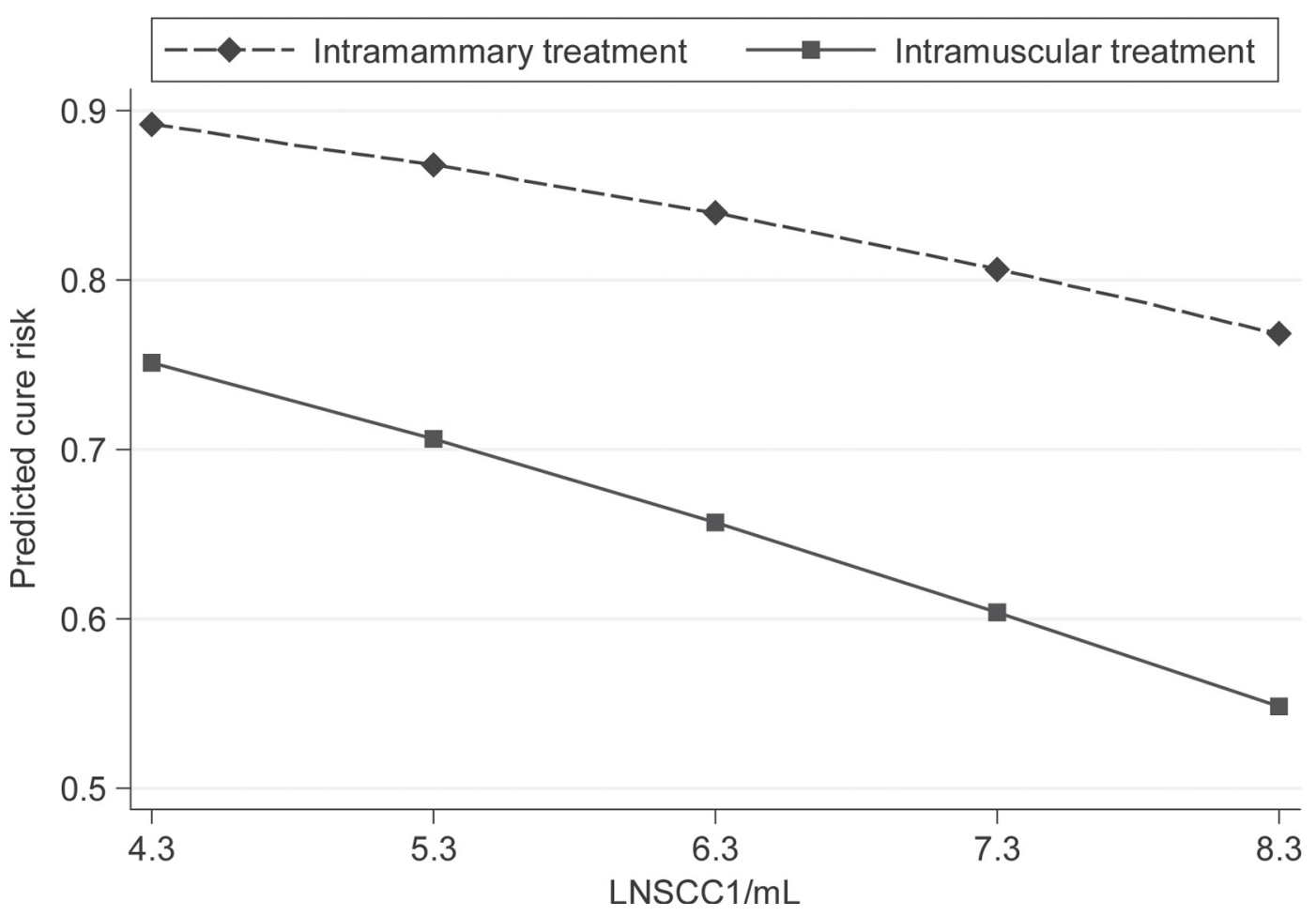

Figure 1. Marginal prediction of the log odds of Streptococcus agalactiae cure comparing intramammary treatment (Masticillin Lactation, Bayer, Leverkusen, Germany) and intramuscular treatment (Mamyzin P, Boehringer Ingelheim GmbH, Ingelheim, Germany) in an average herd given the cow initial SCC values (LNSCC1; natural logarithm of the individual somatic cell count at the beginning of the intervention).

samples were chosen because treatment was at the cow rather than the quarter level and composite samples were more economical. Considering the high shedding levels typical of a $S$. agalactiae infection, minimal loss of sensitivity is associated with composite samples (Dinsmore et al., 1991). Indeed, because a tendency for multiple quarters to be infected within a cow exists, treatment of all 4 quarters is often recommended to avoid missed infections based on a quarter-level diagnoses (Dinsmore et al., 1991). Prescreening the herds using BTSCC and bulk tank culture was successful in identifying herds with high $S$. agalactiae prevalence. Due to the low self-cure rate for S. agalactiae (Grommers et al., 1985; Wilson et al., 1999), no negative controls were included. During the present study, a single posttreatment sample was taken to determine cure risk because the time restriction imposed by retreatment of refractory cases limited our ability to take a second posttreatment sample. The reported sensitivity of $S$. agalactiae culture is high (95\%) compared with other pathogens (Keefe, 2012); therefore, there is less benefit to using 2 samples to define cure. High sensitivity of bacterial culture for detection of $S$. agalactiae is the result of the continuous high bacterial shedding of the $S$. agalactiae (Keefe, 2012). A single sample might result in an overestimate of the cure risk but, given the high sensitivity of culture, this effect is likely quite small. Additionally, we anticipate that both treatments groups would be equally affected by any misclassification.

According to the results of the current study, the cure risk for subclinical $S$. agalactiae infection after a single course of therapy was significantly higher for the IMM product compared with the IM treatment. This data contrasts with McDougall (1998), where both clinical and subclinical IMM infections caused by major gram-positive pathogens were treated with either subcutaneous penethamate and IMM penicillindihydrostreptomycin and no significant differences were observed; however, S. agalactiae was not among the pathogens considered (McDougall, 1998). In a second study, focused exclusively on clinical mastitis, Sérieys et al. (2005) also reported no significant difference between IM treatment with penethamate and IMM ampicillin and cloxacillin treatment, although their study included multiple pathogen species and the frequency of $S$. agalactiae was low (7 out of 312 cases for the evaluation of bacteriological cure). Finally, another study found no difference in cure risk between IM benzyl penicillin potassium and IMM penethamate for the most common penicillin sensitive udder pathogens $(S$. 
aureus, Streptococcus dysgalactiae, and Streptococcus uberis), but once again this data set did not include $S$. agalactiae (Sandgren et al., 2008). Our study focused exclusively on $S$. agalactiae and, therefore, had more appropriate statistical power to document the differences between IM and IMM for that pathogen. Cure rates differences for the treatment routes may be related to the $S$. agalactiae infection site. Streptococci, particularly $S$. agalactiae, remain in the milk compartment or in the milk ducts as opposed to invasion of the udder parenchyma (Pyörälä, 2006). The IMM product may reach higher concentrations in the milk compartment were the $S$. agalactiae is present, giving the antimicrobial more opportunity to eliminate the infection (Pyörälä, 2006).

The efficacy of the IM penethamate-based product was $65.8 \%$ in our study, which was higher than reported by Salat et al. (2008). The earlier study considered subclinical mastitis produced by several mastitis pathogens (S. aureus, CNS S. uberis, non-S. agalactiae streptococci, and Corynebaterium bovis). When evaluated against a negative control, treatment with IM penethamate had a bacteriological cure risk of 52.2 compared with $10.9 \%$ in the control group (Salat et al., 2008). The present study focused on S. agalactiae only, and therefore the cure risk would be expected to be higher when compared with other major pathogens, such as $S$. aureus. The treatment outcome of the IM product in the current study may have been superior than previously reported due to the targeted microorganism, which is frequently reported as sensitive in the literature (Keefe, 1997).

The efficacy of the IMM product in our study was $82.4 \%$. This finding agrees with a review article from Keefe (1997), which reported lactational therapy cure risks for IMM treatment for $S$. agalactiae between 84 and $100 \%$. Also cited in the review, the efficacy of cloxacillin IMM treatment in the form of blitz therapy achieved cure risks of 98 and $100 \%$ according to 2 studies (Kingwill et al., 1970; Thomson et al., 1988). Furthermore, in an evaluation of several IMM therapies, Wilson et al. (1999) reported a cure risk for subclinical S. agalactiae infection of $77 \%$ for cloxacillin and $86 \%$ for amoxicillin, as well as a spontaneous cure risk of $27 \%$.

In contrast to the difference observed between the products for the initial therapy, the retreatment cure risk was very similar between the protocols. The outcome of the additional treatment is in agreement with Sérieys et al. (2005), who reported a similar bacteriological cure risk for IMM and IM treatments among cows treated for a second time (Sérieys et al., 2005). A S. uberis therapy study reported similar cure rates as the current study for retreatment of refractory cases (55\%; Milne et al., 2005). The reasons for the differing outcomes for initial treatment versus retreatment are not clear. The initial treatment may have cured the most vulnerable infections, leaving a subpopulation of infections with either pathogen or individual cow factors that resulted in the lower cure risk in these retreated animals. Additionally, the cure risks were much lower than expected (i.e., used for the calculation of the sample size) based on previously reported cure risks (Kingwill et al., 1970; Thomson et al., 1988). This observation could be related to the presence of long-standing infections associated with higher SCC. Also, the strain variability of $S$. agalactiae expressing differences in pathogenicity and virulence factors could be an element leading to lower cure risks in the present study (Sorensen et al., 2010).

Furthermore, the overall failure to cure risk could be related to both the persistence of infections (true failures) and reinfection events. To differentiate persistence versus reinfection, fingerprinting methods have been used for pathogens where a diverse within-herd pathogen population is expected (e.g., environmental source Streptococcus uberis; Milne et al., 2005). However, with a pathogen with less expected genetic diversity within a herd, such as $S$. agalactiae, this technique would be less helpful. Because treatment was balanced within each herd, we anticipated that the risk of reinfection would be equal between the treatment assignments.

Total exposure to antibiotics is an important consideration when designing treatment protocols. Total antibiotic consumption has been reported to be higher for IM compared with IMM treatments (Hillerton and Kliem, 2002), and IMM has been shown to have a higher local concentration in the mammary gland (Pyörälä, 2006; Barkema et al., 2006). Consequently, the route of administration is an important factor to minimize the antimicrobial use (Sandgren et al., 2008). Routine use of antibiotics is an important condition leading to the increase in resistant bacterial strains (Kolár et al., 2001), especially in herds with high SCC and high antimicrobial use (Sandgren et al., 2008). This is a factor that should be controlled for through careful selection of targeted herds and individuals to be treated, including, for example, not treating cows with a poor prognosis (Sandgren et al., 2008). Much of the success for treatment of $S$. agalactiae relies on this pathogen's high degree of antibacterial susceptibility and the fact that it is an obligate udder pathogen located in the milk ducts (Erskine et al., 2003), which can be easily reached with IMM administration and requires lower amounts of antimicrobial. Additional information suggests that the systemic treatment for streptococcal mastitis usually 
results in clinical cure but with lower bacteriological cure (Ziv, 1980); this can be due to subinhibitory concentrations of the product when administered systemically and is also cited as a potential factor for resistance development (Tello et al., 2012). The efficacy of an IM product depends on its effective passage from the blood into the foci of infection and on the maintenance of therapeutic concentrations at the target site (Pyörälä, 2006). To assess the level of exposure of the infecting organism to the antibiotic, it is necessary to determine the concentration of antibiotic in the milk (Ziv, 1980); nonetheless, this was not performed in our study. In another study, IM penicillin G was given to treat $S$. agalactiae infections at 3 different concentrations (Murphy and Stuart, 1954). The authors reported that the application of an aqueous suspension of 42,000,000 IU, with a first dose of $6,000,000$ IU followed by 12 doses of 3,000,000 IU at 12-h intervals, completely eliminated $S$. agalactiae infection, but it was not sufficiently high to eliminate Corynebacterium bovis (Murphy and Stuart, 1954). Therefore, to achieve a complete bacteriological cure when using an IM product, larger amounts of active compound were required to attain inhibitory levels in the mammary gland. In the present study, the protocol for antibiotic exposure for IM cases was $12,127.5 \mathrm{mg}$ per complete course of treatment versus $3,300 \mathrm{mg}$ per course of treatment for the IMM product. Whereas it is difficult to assess directly the effect of this difference, because different drugs are involved in each protocol, this is an apparent additional benefit (beyond improved efficacy) for the IMM-based therapy.

The IMM treatment group showed a higher cure risk than the IM group, but in both cases, the cure risk was affected by the initial SCC of the cow (Figure 1). This finding is in agreement with Weaver et al. (1986), where they observed a significantly lower cure rate for $S$. agalactiae in cows with California Mastitis Test $\geq 1$ when compared with cows with a trace or negative California Mastitis Test score (Weaver et al., 1986). A similar finding was reported by Owens et al. (1988), where increasing SCC was associated with a lower chance of cure for S. aureus (Owens et al., 1988). Barkema et al. (2006) also reported that cow-level SCC and the period of time that SCC remained elevated were associated with the cure risk of pathogen (Barkema et al., 2006).

Cure risk is also influenced by herd-level risk factors (Weaver et al., 1986). However, in the present study, herd only contributed to $5 \%$ of the total variability in cure risk, suggesting a minimal herd effect. Other possible predictors of interest not measured in our trial, for example DIM and parity, could affect the cure risks in both treatments. Related to these 2 variables, other authors have reported no influence of the stage of lactation on the cure risk for the penethamate or negative control groups for non-agalactiae streptococci, S. aureus, and CNS (Salat et al., 2008). In contrast, another group of authors reported that for $S$. aureus treatment, increasing parity was associated with lower cure risk (Barkema et al., 2006). Moreover, Deluyker et al. (2005) showed that bacteriological cure was higher for lower-parity cows treated with different regimens of pirlimycin hydrochloride for streptococci and $S$. aureus subclinical infections, but no $S$. agalactiae were found in that study (Deluyker et al., 2005).

In the present study, within each farm, the treatment allocation was balanced and performed randomly for all the subjects in the trial. This should result in a relatively equal distribution of independent variables, such as stage of lactation and parity in both treatment groups or unmeasured confounders that could bias the estimated effects (Dohoo et al., 2009). In addition, including herd as a random effect will help to control for other unmeasured confounders that cluster at the farm level. A previous study found no effect of DIM on the cure risk for streptococci and other major pathogens (Salat et al., 2008); however, the present study did not control by these variables due to the difficulties retrieving the individual records for the cows. In addition, the logistic model presented in our study included herd as random effect, and this will also reduce the effect of herd-level unmeasured confounders. According to the low ICC obtained from the data, minimal clustering occurred and most of the variation was within groups (Dohoo et al., 2009).

\section{CONCLUSIONS}

This study showed that the IMM treatment regimen performed better than the IM in terms of bacteriological cure risk, despite the reported high susceptibility of this specific pathogen to both $\beta$-lactams active ingredients: cloxacillin and ampicillin (IMM) and penethamate hydriodide (IM). Overall exposure to antibiotics for the cow was lower for the IMM treatment, although direct comparison across differing antibiotics is difficult because the relative importance of each in developing resistance may be different. Additionally, the initial treatment cure risks, for both protocols, were influenced by the initial SCC of the cow. Treatment protocol including route of administration, as well as cow SCC, should be considered when making management decisions (treatment and culling) for cows infected with S. agalactiae.

\section{ACKNOWLEDGMENTS}

The authors thank William Chalmers [Department of Health Management, Canada Excellence Research 
Chair in Aquatic Epidemiology (CERC), Atlantic Veterinary College, University of Prince Edward Island, Canada] and Marguerite Cameron (Department of Health Management, Atlantic Veterinary College) for technical assistance in preparation of the manuscript, and to Victor Guzman (Bayer Animal Health, Colombia) and Omar Archila (Boehringer Ingelheim, Colombia), who donated the antimicrobials used in this trial.

\section{REFERENCES}

Barkema, H. W., Y. H. Schukken, and R. N. Zadoks. 2006. Invited review: The role of cow, pathogen, and treatment regimen in the therapeutic success of bovine Staphylococcus aureus mastitis. J. Dairy Sci. 89:1877-1895. http://dx.doi.org/10.3168/jds.S00220302(06)72256-1.

Comesaña, A., E. Bermo Vizcaya, J. L. Alvarez Villar, J. Ben Lameiro, J. M. Bornot Sánchez, and E. G. Hechavarria Estrada. 2012. EPIDAT 4.0. Xunta de Galicia, A Coruña, Spain.

Deluyker, H. A., S. N. Van Oye, and J. F. Boucher. 2005. Factors affecting cure and somatic cell count after pirlimycin treatment of subclinical mastitis in lactating cows. J. Dairy Sci. 88:604-614.

Dinsmore, R. P., P. B. English, R. N. Gonzalez, P. M. Sears, and H. F. Schulte. 1991. Evaluation of methods for the diagnosis of Streptococcus agalactiae intramammary infections in dairy cattle. J. Dairy Sci. 74:1521-1526. http://dx.doi.org/10.3168/jds.S00220302(91)78312-4.

Dohoo, I. R., S. W. Martin, and H. Stryhn. 2009. Veterinary Epidemiologic Research. 2nd ed. VER Inc., Charlottetown, PE, Canada.

Du Preez, J. H. 2000. Bovine mastitis therapy and why it fails: Continuing education. J. S. Afr. Vet. Assoc. 71:201-208.

Duarte, R. S., O. P. Miranda, B. C. Bellei, M. A. V. P. Brito, and L. M. Teixeira. 2004. Phenotypic and molecular characteristics of Streptococcus agalactiae isolates recovered from milk of dairy cows in Brazil. J. Clin. Microbiol. 42:4214-4222. http://dx.doi. org/10.1128/JCM.42.9.4214-4222.2004.

Edmondson, P. 2011. Blitz therapy for the eradication of Streptococcus agalactiae infections in dairy cattle. In Pract. 33:33-37. http:// dx.doi.org/10.1136/inp.c7449.

Erskine, R. J., S. Wagner, and F. J. DeGraves. 2003. Mastitis therapy and pharmacology. Vet. Clin. North Am. Food Anim. Pract. 19:109-138. http://dx.doi.org/10.1016/S0749-0720(02)00067-1.

Erskine, R. J., R. D. Walker, C. A. Bolin, P. C. Bartlett, and D. G. White. 2002. Trends in antibacterial susceptibility of mastitis pathogens during a seven-year period. J. Dairy Sci. 85:1111-1118. http://dx.doi.org/10.3168/jds.S0022-0302(02)74172-6.

Gianneechini, R., C. Concha, R. Rivero, I. Delucci, and J. Moreno López. 2002. Occurrence of clinical and sub-clinical mastitis in dairy herds in the West Littoral Region in Uruguay. Acta Vet. Scand. 43:221-230.

Gröhn, Y. T., D. J. Wilson, R. N. González, J. A. Hertl, H. Schulte, G. Bennett, and Y. H. Schukken. 2004. Effect of pathogen-specific clinical mastitis on milk yield in dairy cows. J. Dairy Sci. $87: 3358-3374$

Grommers, F. J., D. Van de Geer, and C. A. in't Veen. 1985. Duration of bovine intramammary infections in commercial dairy herds. Vet. Rec. 116:581-584

Gruet, P., P. Maincent, X. Berthelot, and V. Kaltsatos. 2001. Bovine mastitis and intramammary drug delivery: Review and perspectives. Adv. Drug Deliv. Rev. 50:245-259.

Hillerton, J. E., and K. E. Kliem. 2002. Effective treatment of Streptococcus uberis clinical mastitis to minimize the use of antibiotics. J. Dairy Sci. 85:1009-1014. http://dx.doi.org/10.3168/jds.S00220302(02)74161-1.

Hogan, J., and R. N. Gonzales, R. Harmon, S. C. Nickerson, J. Pankey, and K. Smith. 1999. Laboratory Handbook on Bovine Mastitis. Rev. ed. National Mastitis Council Inc., Madison, WI.
Katholm, J., T. W. Bennedsgaard, M. T. Koskinen, and E. Rattenborg. 2012. Quality of bulk tank milk samples from Danish dairy herds based on real-time polymerase chain reaction identification of mastitis pathogens. J. Dairy Sci. 95:5702-5708. http://dx.doi. org $/ 10.3168 /$ jds.2011-5307.

Keefe, G. 2012. Update on control of Staphylococcus aureus and Streptococcus agalactiae for management of mastitis. Vet. Clin. North Am. Food Anim. Pract. 28:203-216. http://dx.doi.org/10.1016/j. cvfa.2012.03.010.

Keefe, G., M. Chaffer, A. Ceballos, M. Londoño, M. Jaramillo, and M. Toro. 2011. Effects of Streptococcus aqalactiae on the Colombian dairy industry. Pages 156-159 in 3rd Int. Symp. Mastitis Milk Qual. National Mastitis Council, St. Louis, MO.

Keefe, G. P. 1997. Streptococcus agalactiae mastitis: A review. Can. Vet. J. 38:429-437.

Kingwill, R. G., F. K. Neave, F. H. Dodd, T. K. Griffin, D. R. Westgarth, and C. D. Wilson. 1970. The effect of a mastitis control system on levels of subclinical and clinical mastitis in two years. Vet. Rec. 87:94-100

Kolár, M., K. Urbánek, and T. Látal. 2001. Antibiotic selective pressure and development of bacterial resistance. Int. J. Antimicrob. Agents 17:357-363. http://dx.doi.org/10.1016/S09248579(01)00317-X

Makovec, J. A., and D. P. L. Ruegg. 2003. Antimicrobial resistance of bacteria isolated from dairy cow milk samples submitted for bacterial culture: 8, 905 samples (1994-2001). J. Am. Vet. Med. Assoc. 222:1582-1589.

McDougall, S. 1998. Efficacy of two antibiotic treatments in curing clinical and subclinical mastitis in lactating dairy cows. N. Z. Vet. J. 46:226-232. http://dx.doi.org/10.1080/00480169.1998.36094.

Milne, M. H., A. M. Biggs, D. C. Barrett, F. J. Young, S. Doherty, G T. Innocent, and J. L. Fitzpatrick. 2005. Treatment of persistent intramammary infections with Streptococcus uberis in dairy cows. Vet. Rec. 157:245-250.

Murphy, J. M., and O. M. Stuart. 1954. The treatment of Streptococcus agalactiae infection of the bovine udder by the intramuscular administration of penicillin. Cornell Vet. 44:139-147.

Owens, W. E., J. L. Watts, R. L. Boddie, and S. C. Nickerson. 1988. Antibiotic treatment of mastitis: Comparison of intramammary and intramammary plus intramuscular therapies. J Dairy Sci. 71:3143-3147. http://dx.doi.org/10.3168/jds.S00220302(88)79915-4.

Pyörälä, S. 2006. Treatment of clinical mastitis: Local and/or systemic? Short or long? Pages 250-259 in Proc. 24th World Buiatrics Congr., Nice, France. World Association for Buiatrics, Paris, France.

Ramírez, N. F., G. Keefe, I. Dohoo, J. Sánchez, O. Arroyave, J. Cerón, M. Jaramillo, and L. G. Palacio. 2014. Herd- and cow-level risk factors associated with subclinical mastitis in dairy farms from the High Plains of the northern Antioquia, Colombia. J. Dairy Sci. http://dx.doi.org/10.3168/jds.2013-6815.

Salat, O.. F. Serieys, B. Poutrel, L. Durel, and L. Goby. 2008. Systemic treatment of subclinical mastitis in lactating cows with penethamate hydriodide. J. Dairy Sci. 91:632-640. http://dx.doi. org/10.3168/jds.2007-0174.

Sandgren, C. H., K. P. Waller, and U. Emanuelson. 2008. Therapeutic effects of systemic or intramammary antimicrobial treatment of bovine subclinical mastitis during lactation. Vet. J. 175:108-117. http://dx.doi.org/10.1016/j.tvjl.2006.12.005.

Sérieys, F., Y. Raguet, L. Goby, H. Schmidt, and G. Friton. 2005 Comparative efficacy of local and systemic antibiotic treatment in lactating cows with clinical mastitis. J. Dairy Sci. 88:93-99.

Sorensen, U.B.S., K. Poulsen, C. Ghezzo, I. Margarit, and M. Kilian. 2010. Emergence and global dissemination of host-specific Streptococcus agalactiae clones. mBio 1:e00178-10. http://dx.doi. org/10.1128/mBio.00178-10.

StataCorp. 2011. Stata Statistical Software. StataCorp LP, College Station, TX.

Tello, A., B. Austin, and T. C. Telfer. 2012. Selective pressure of antibiotic pollution on bacteria of importance to public health. Envi- 
ron. Health Perspect. 120:1100-1106. http://dx.doi.org/10.1289/ ehp. 1104650

Thomson, J. R., N. Mollison, and K. P. Matthews. 1988. An investigation of mastitis due to Streptococcus agalactiae, Streptococcus uberis and Mycobacterium smegmatis in a dairy herd. Vet. Rec. 122:271-274.

Tyler, J. W., R. C. Wilson, and P. Dowling. 1992. Treatment of subclinical mastitis. Vet. Clin. North Am. Food Anim. Pract. 8:1728.

Weaver, L. D., J. Galland, P. A. Martin, and J. Versteeg. 1986. Treatment of Streptococcus agalactiae mastitis in dairy cows: Comparative efficacies of two antibiotic preparations and factors associated with successful treatment. J. Am. Vet. Med. Assoc. 189:666-669.
Wilkinson, F. C. 1965. Bovine mastitis control in Western Australia. Aust. Vet. J. 41:93-97.

Wilson, D. J., R. N. Gonzalez, K. L. Case, L. L. Garrison, and Y. Grohn. 1999. Comparison of seven antibiotic treatments with no treatment for bacteriological efficacy against bovine mastitis pathogens. J. Dairy Sci. 82:1664-1670.

Zadoks, R. N., J. R. Middleton, S. McDougall, J. Katholm, and Y. H. Schukken. 2011. Molecular epidemiology of mastitis pathogens of dairy cattle and comparative relevance to humans. J. Mammary Gland Biol. Neoplasia 16:357-372. http://dx.doi.org/10.1007/ s10911-011-9236-y.

Ziv, G. 1980. Drug selection and use in mastitis: Systemic vs. local therapy. J. Am. Vet. Med. Assoc. 176:1109-1115. 